\title{
BOMBARDEROS EN PICADO (1941): UN MODELO DE ESTUDIO DE LA FISIOLOGÍA DE LA AVIACIÓN
}

\section{Dive Bomber (1941): a study model of aviation physiology}

\author{
Germán DOMÍNGUEZ-VÍAS \\ Departamento de Fisiología, Facultad de Ciencias de la Salud de Ceuta. Universidad de Granada (España). \\ Correo electrónico: germandv@ugr.es
}

Fecha de recepción: 4 de febrero de 2020

Fecha de aceptación: 25 de febrero de 2020

Fecha de publicación: 15 de diciembre de 2020

\section{Resumen}

Este artículo sirve para iniciarse en las bases docentes de la actual fisiología de la aviación, cuyo origen se remonta al comienzo de la Segunda Guerra Mundial. Bombarderos en picado (1941) de Michael Curtiz es un excelente material docente para ayudar en la comprensión de las distintas causas del síncope de los pilotos en las alturas, permitiendo la reflexión y la búsqueda de soluciones o alternativas a través de experimentos que permiten la recuperación de la homeostasis corporal. Su material audiovisual comparte escenas reales del ejército americano que permiten acceder a estos descubrimientos y al avance del estado actual de la moderna fisiología aeroespacial.

Palabras clave: altitud; hipoxia hipobárica; síncope; aviación.

\section{Abstract}

This article serves to begin in the teaching bases of the current aviation physiology, whose origin dates back to the beginning of World War II. Dive Bomber (1941) by Michael Curtiz is an excellent teaching material to help in the understanding of the different causes of the pilots' syncope at heights, allowing thinking and the search for solutions or alternatives through experiments that allow the recovery of the body homeostasis. His audiovisual material shares real scenes of the United States Army that allow access to these discoveries and the progress of the current state of modern aerospace physiology.

Key words: altitude; hypobaric hypoxia; syncope; aviation. 


\section{Ficha técnica}

Título: Bombarderos en picado.

Título original: Dive Bomber.

País: Estados Unidos.

Año: 1941.

Director: Michael Curtiz.

Música: Max Steiner.

Fotografía: Bert Glennon, Winton C. Hoch.

Montaje: George Amy.

Guión: Frank Wead, Robert Buckner.

Intérpretes: Errol Flynn, Fred MacMurray, Ralph Bellamy, Alexis Smith, Robert Armstrong, Regis Toomey, Allen Jenkins, Craig Stevens, Herbert Anderson, Moroni Olsen, Gig Young, Dennie Moore, Louis Jean Heydt, Cliff Nazarro.

Color: color (Technicolor).

Duración: 132 min.

Género: drama, bélica, II Guerra Mundial, ejército, basado en hechos reales, propaganda.

Idioma original: inglés.

Productora: Warner Bros. Pictures.

Sinopsis: historia de un médico cirujano militar de vuelo y un piloto de alto rango de la Armada de los Estados Unidos que superan las diferencias personales para investigar los mareos y desvanecimientos que sufren los pilotos cuando vuelan a gran altura, con el fin de trabajar en la solución del problema de la enfermedad de la altitud, desarrollando un traje de gran altitud que protegerá a los pilotos de desmayarse cuando caen en picado. Basada en hechos reales, fue estrenada meses antes del ataque japonés contra Pearl Harbor.

Premios: Premios Academia (EE.UU.): Nominación al Oscar por mejor fotografía en color (Bert Glennon, 1942).

Enlaces:

h t t p s://ww w.imdb.com/title/ tt0033537/?ref_=ttawd_awd_tt https://www.filmaffinity.com/es/film898574. html

\section{Trailer internacional (original)}

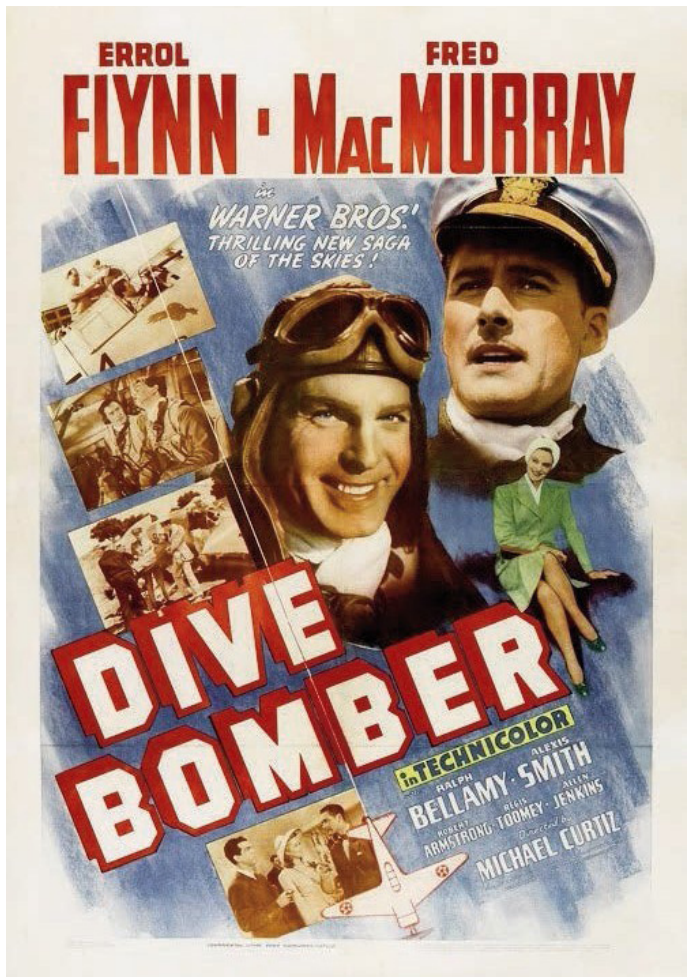

Cartel de la versión americana Dive bomber (1941).

\section{Introducción}

Justo al comienzo de Bombarderos en picado / Dive bomber (1941) de Michael Curtiz se especifica que «esta película está dedicada a los médicos pioneros de las fuerzas aéreas, en reconocimiento a los esfuerzos heroicos para resolver los complicados problemas de la medicina en aviación». Es sabido que uno de los mayores retos de la homeostasis de la fisiología humana era la ascensión a alturas cada vez mayores ${ }^{1}$. El cuerpo humano es sometido a problemas derivado de los efectos de la propia altura y de las bajas presiones de gases, sin embargo, suponen desafíos mayores a un piloto de avión si le sumamos, junto a las grandes alturas, las fuerzas de aceleración. Esto mismo se observa durante ejercicios de bombardeos en picado a partir de 600 metros de altura sobre el nivel del 


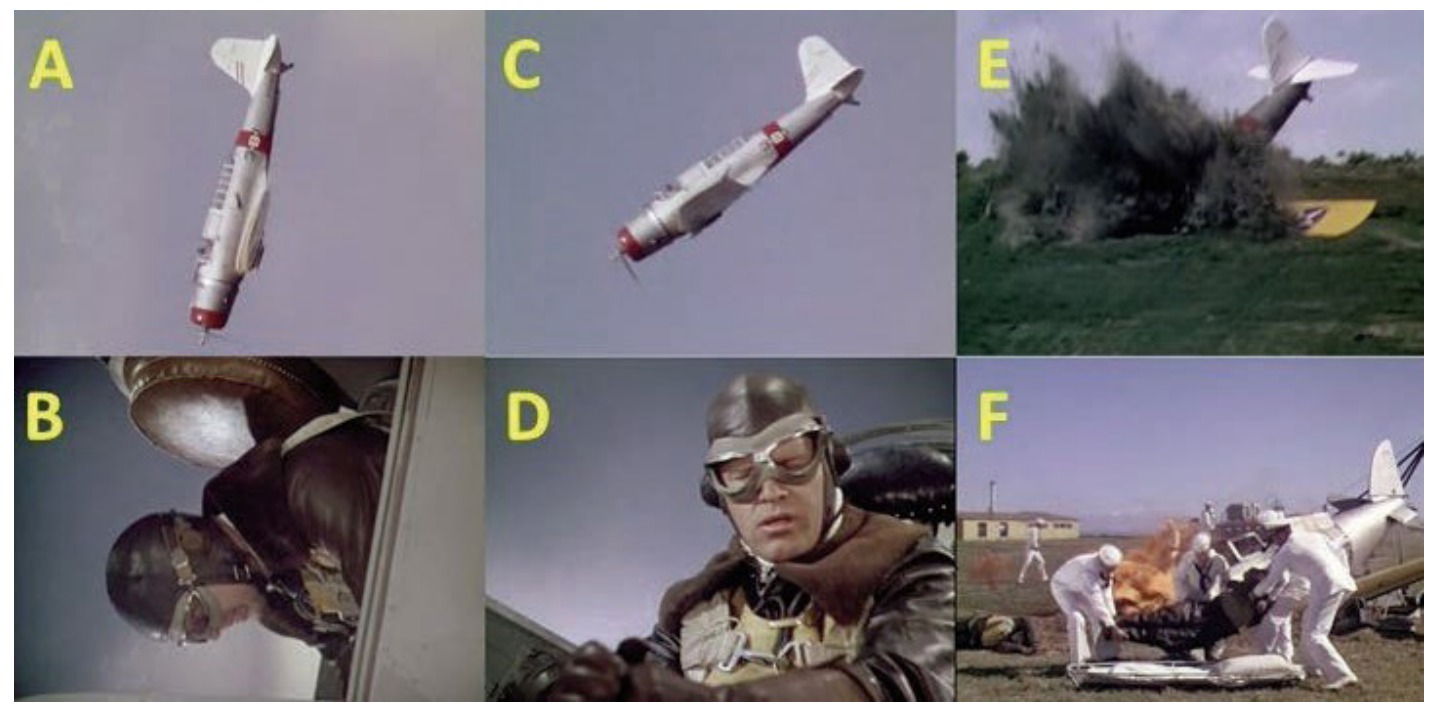

Foto 1. Ejercicio en picada a 600 m.s.n.m. (A-B) y corrección de la trayectoria (C), con resultado de desmayo (D) e impacto fatal en el suelo (E-F).

mar (m.s.n.m.). Durante el minuto 12 (12':04"), las maniobras de descenso en picada y su posterior corrección en la trayectoria afectaban al piloto de combate iniciando síntomas de malestar y concluyendo con pérdida de conocimiento (síncope) e impacto sobre el suelo (Foto 1), siendo la causa común de lesiones medulares y/o posterior fallecimiento por elevación de presión intracraneal durante el procedimiento quirúrgico.

La primera vértebra cervical (C1 o atlas) posee la mayor movilidad de toda la columna vertebral, y las articulaciones entre el hueso occipital y el atlas (CO-C1) y entre el atlas y el axis (C1-C2), anatómicamente muy especializadas, están biomecánicamente estructuradas con un elevado rango de movilidad, además de ser el nexo de unión osteoligamentoso entre la cabeza y el tronco. Sin embargo, las hace más vulnerables con mayor probabilidad de daño frente a numerosos procesos patológicos ${ }^{2}$. Los traumatismos sobre el complejo C0-C1-C2 pueden provocar lesiones musculares, ligamentosas, articulares u óseas; en muchos casos existen lesiones mixtas con una evolución peyorativa y con posibilidad de afectación medulovascular ${ }^{3,4}$, configurando los diversos tipos de luxaciones o fracturas de este complejo (Foto 2). Una presión elevada en la columna, entre la base del cráneo y el atlas, solo puede ser liberada si se opera, a pesar de la debilidad de los pacientes y su pérdida de conocimiento. Innecesariamente debe de aparecer en las vértebras cervicales estos síntomas negativos justo tras estrellarse el avión. Las luxaciones cervicales acompañadas de hiperlordosis, fracturas y/o muerte incluso pueden aparecer, durante una fracción de segundo, en el ambiente de trabajo de los pilotos ${ }^{2}$, durante el lanzamiento del asiento eyectable, vibraciones violentas, o por el aumento de las fuerzas $G$ a través de aceleraciones y giros bruscos ${ }^{5}$. Las luxaciones y traumatismos del complejo C0-C1-C2 más relevantes son los que se detallan a continuación.

\section{Luxación occipitoatloidea}

Se produce por la ruptura total de los ligamentos y cápsulas articulares que unen el atlas

Rev. Med. Cine. 2020; 16(4), 261-277 Ediciones Universidad de Salamanca / @®@ J. Med. Mov., 2020; 16(4), 261-277 
y la odontoides al hueso occipital con la consiguiente dislocación de éstos, en accidentes a alta velocidad $^{6}$. La separación traumática entre el atlas y el hueso occipital en la mayoría de los casos es incompatible con la vida, ya que puede ocasionar la sección de la médula o de las arterias vertebrales. Estas lesiones pueden asociarse a fracturas de la punta de la odontoides. La luxación atlooccipital es una lesión muy inestable que puede ocasionar distracción o compresión de la médula espinal, tronco cerebral o de pares craneales y alteraciones vasculares por estiramiento de las arterias vertebrales. Clínicamente puede manifestarse por paresias de los nervios VI, X y XII pares craneales, monoparesias, hemiparesias o tetraparesias, o disfunción respiratoria. También puede provocar una tetraplejia completa con apnea. Son lesiones que prácticamente no tienen ninguna posibilidad de curación espontánea. La cirugía mediante una fijación instrumentada occipitocervical o, en ocasiones, una fijación interarticular posterior atlooccipital ${ }^{7,8}$ logra una correcta alineación y estabilización de la luxación y así impide la aparición o empeoramiento de la clínica neurológica.

\section{Fracturas del atlas}

Representan del $4-15 \%$ de todas las fracturas de la columna cervical y del $1-3 \%$ de todas las fracturas de la columna vertebral. Un $39-56 \%$ se presentan como fracturas aisladas y en un $50 \%$ de los casos se asocian a fracturas del axis. Dada la especial configuración anatómica del atlas, los traumatismos sobre esta vértebra pueden producir una considerable combinación de lesiones sobre las masas o los arcos anteriores, posteriores y/o laterales de esta vértebra (Foto 2 ), lesiones ya clasificadas por Jefferson ${ }^{9}$ en 1920. Los pacientes con fracturas aisladas del atlas que llegan a hospital casi nunca presentan síntomas neurológicos. Existen pocos datos para sospechar una fractura

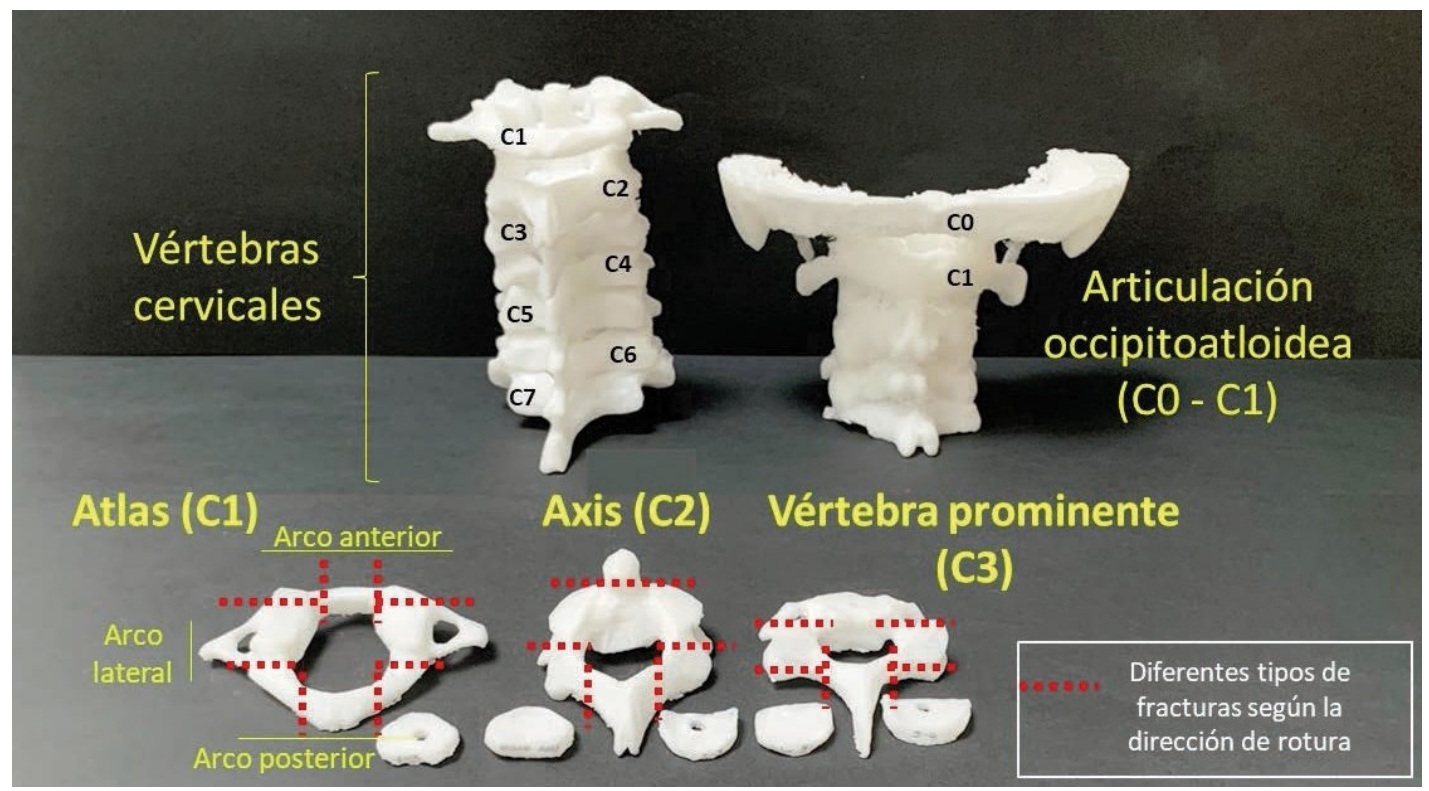

Foto 2. Réplicas impresas en 3D de la base del cráneo (hueso occipital o C0) que articula con la primera vértebra cervical ( $\mathrm{C} 1 \mathrm{o}$ atlas) y este a su vez con la segunda vértebra cervical (C2 o axis). Se muestra en rojo todas las posibles fracturas unilaterales o bilaterales de cada arco vertebral.

Rev. Med. Cine. 2020; 16(4), 261-277 Ediciones Universidad de Salamanca / @@@

J. Med. Mov., 2020; 16(4), 261-277 
del atlas en los pacientes traumáticos que llegan al hospital inconscientes. En los pacientes lúcidos, el mecanismo del accidente, junto a la presencia de contractura y dolor cervical, limitación de los movimientos de la cabeza, dolor suboccipital, o anestesia o neuralgia occipital pueden orientar el diagnóstico. La presencia de un hematoma retrofaríngeo puede sospecharse ante la presencia de disfagia o disartria.

\section{Fracturas del axis}

Representan hasta el $17 \%$ de todas las fracturas cervicales. De éstas, un $55 \%$ son fracturas de la apófisis odontoides, un $23 \%$ son fracturas de los pedículos y un $22 \%$ asientan en el cuerpo del axis o en otras localizaciones menos frecuentes.

\section{Fracturas de la apófisis odontoides (AO)}

Es el tipo de fractura más frecuente de la columna cervical alta. La fractura de la base de la odontoides es tremendamente inestable y con una peligrosidad evolutiva enorme si no se logra su consolidación. La gran mayoría de los pacientes que llegan con fracturas de las apófisis odontoides (AO) están neurológicamente indemnes ${ }^{10,11}$. Sin embargo, es un tipo de fractura que puede producir la muerte por cizallamiento medular o graves lesiones neurológicas en el momento del accidente $^{3,12}$. Puede aparecer clínica de mielopatía cervical tardía en semanas, meses o incluso años después de producirse la fractura ${ }^{13,14}$. Aquellos pacientes asintomáticos neurológicamente que con un correcto tratamiento consiguen la reducción, fijación y fusión ósea de su fractura, consiguen la curación de estas graves lesiones ${ }^{10}$.

La rotura del istmo (también conocido como pars interarticularis - partes interarticulares-) del axis favorece la espondilolisis, de forma que la apófisis articular queda separada del cuerpo vertebral ${ }^{15}$. Las fracturas que asientan en los elementos posteriores de la segunda vértebra cervical se conocen también con la denominación de fractura de la "pars interarticularis», espondilolistesis traumática del axis o fractura de Hangman. Es un tipo de fractura que, en su mayor expresividad, se presenta en los reos condenados a la horca, fractura que en estos casos se asocia a una brutal luxación C2-C3 por un mecanismo de hiperextensión-distracción. También puede presentarse por un mecanismo de hiperextensióncompresión en accidentes de circulación o caídas, similares en ahorcados. El objetivo en las fracturas de Hangman provocadas por ahorcamiento es la muerte del reo por cizallamiento medular y de las arterias vertebrales. Como complicación de la espondilólisis, y causa frecuente de dolor, aparece la espondilolistesis o el deslizamiento de una vértebra sobre otra.

\section{Fracturas y luxaciones asociadas atloaxoideas}

La existencia de fracturas ${ }^{16}$ y luxaciones ${ }^{17}$ combinadas de atlas y axis es relativamente frecuente, además de evidente en pilotos de avión de combate y helicópteros ${ }^{18}$. Desde el punto de vista anatomofisiopatológico y de los mecanismos lesionales de la biomecánica clínica, para la producción de estas lesiones son necesarias fuerzas patomecánicas muy importantes que normalmente implican la coexistencia de un mayor número de déficits neurológicos (12\%) que en el caso de fracturas aisladas del atlas (0\%) o del axis (2\%). La combinación de fracturas de atlas y axis se presenta en el $15 \%$ de las fracturas de la odontoides y en el $9 \%$ de las fracturas de los pedículos del axis ${ }^{3,4}$. Se han descrito numerosas posibilidades de combinaciones, pero las más frecuentes son: fracturas de atlas y de la base de la apófisis odontoides (40\%), fracturas de atlas y fracturas del cuerpo del axis (28\%), fracturas de atlas y transversas de axis (20\%), fracturas de atlas y de los pedículos de axis (12\%) o fracturas de la apófisis odontoides asociada a ruptura del ligamento transverso del atlas ${ }^{3,4}$. La gran mayoría de estas fracturas son inestables. 


\section{Síncopes}

En plena Segunda Guerra Mundial, los desmayos en bombarderos en picado eran interesantes tanto para los médicos del ejército de EE.UU. como de Alemania. El vuelo a más de 9.000 m.s.n.m. suponía fallecimientos por estrellarse sin causas aparentes, achacadas al mal de altura con la pérdida de la consciencia, mareo por hipoxia hipobárica e hipotermia ${ }^{1}$. Instantes después del conflicto bélico, descubrieron que la exposición a una alta aceleración sostenida (+G o carga de inercia de pies a cabeza) tiene efectos nocivos en el cuerpo de los pilotos en vuelo, creando fuerzas que actúan sobre un piloto entre cinco a diez veces más fuerte que la gravedad. El efecto más importante de la aceleración centrífuga $(+G$ o fuerza G) sobre el cuerpo se produce a nivel del sistema circulatorio ${ }^{19}$, porque la sangre es móvil y se puede desplazar por las fuerzas centrífugas. Un aviador sentado en el asiento de su carlinga, la fuerza con la que comprime el asiento se debe a la fuerza de la gravedad y es igual a su peso $(+1$ G). Si la fuerza con la que comprime el asiento se hace cinco veces su peso normal durante la salida de un picado, la fuerza que es sometida sobre el asiento es mayor ( $+5 \mathrm{G}$ ), desplazándose la sangre de la parte superior del cuerpo hacia los vasos de la parte más inferior del cuerpo, dilatándose pasivamente hasta alcanzar una presión venosa de $\sim 300 \mathrm{mmHg}$ (o de $\sim 450 \mathrm{mmHg}$ si permanece de pie e inmóvil). Al comienzo de la aceleración, el efecto de la fuerza $\mathrm{G}(+4 \mathrm{G} /+6 \mathrm{G})$ en un piloto acontece con pér- dida visual (velo negro) y de conciencia por un déficit de presión de perfusión cerebral (PPC o presión sanguínea necesaria para perfundir el tejido nervioso para un buen funcionamiento metabólico). Como el corazón no puede bombear salvo que la sangre vuelva a su interior, cuanto mayor sea la cantidad de sangre que se estanca en la parte inferior del cuerpo menor será la cantidad de sangre disponible para el gasto cardíaco. Tanto la presión sistólica como diastólica disminuyen muy por debajo de lo normal (PS y PD:
$<22 \mathrm{mmHg}$ ) al inicio de los primeros segundos de la aceleración $(+3,3 \mathrm{G})$, pero como respuesta a la pérdida de la homeostasis, a continuación se activa, de forma rápida, el reflejo barorreceptor para ayudar a restablecer un poco estas presiones (PD: $55 \mathrm{mmHg}$; PD: 20 mmHg). Aceleraciones mayores de $+4 \mathrm{G}$ a $+6 \mathrm{G}$ ocurridos en un rango de tiempo después de la ceguera y la inconciencia son peligrosas por incrementar el rango de letalidad. Otros datos clínicos que ocurren en pilotos, y cuya causa precisa sigue sin estar definida, es la presencia de cambios en la ondas eléctricas del corazón ${ }^{20}$ y disfunción hepática con afección de su morfología y actividad metabólica ${ }^{21}$.

Esta película relata toda la experimentación llevada a cabo hasta el descubrimiento de la causa de los desmayos y la prevención de la pérdida de irrigación en el cerebro. En el minuto 21 (21':30"), una de las primeras opciones que consideraban para lucha contra el síncope era reducir la velocidad en picada con los flaps (superficies que se encuentran en las alas que permiten aumentar la sustentación del avión reduciendo la velocidad en maniobras de despegue y aterrizaje). Como los resultados no eran los esperados, a partir del minuto $33\left(33^{\prime}: 40^{\prime \prime}\right)$, se relata los ejercicios prácticos para el entrenamiento del aviador del libro de vuelo del piloto, realizando (Foto 3): (a) espirales, (b) aterrizajes, (c) acrobacias, (d) giros, (e) recuperación rápida (caída en picado, girando, hasta enderezar el avión), (f) experimentos en cámara hipobárica para el estudio de las curvas de disociación de oxihemoglobina, en relación a las presión parcial de oxígeno $\left(\mathrm{PO}_{2}\right)$ y la saturación de oxígeno a la hemoglobina, y los efectos de la presión parcial de anhídrido carbónico $\left(\mathrm{PCO}_{2}\right), \mathrm{pH}$ y temperatura en la curva de disociación de oxígeno (efecto Bohr). Este tipo de cámaras hipobárica son bastante utilizadas para el entrenamiento de los pilotos militares, simulando la descompresión en cabina y la hipoxia de las grandes alturas ${ }^{22}$. Un piloto que respira aire en un avión no presurizado no puede ascender hasta alturas mucho mayores 
que uno que respira oxígeno puro, pudiendo permanecer consciente hasta que la saturación arterial de oxígeno disminuya hasta el techo de $50 \%$ ( 7.000 m.s.n.m.). La saturación de oxígeno en la hemoglobina de la sangre arterial cuando se respira oxígeno puro permanece por encima del $90 \%$ hasta que el piloto asciende hasta los 12.000 m.s.n.m., por ello una despresurización a esta altura provocaría una hipoxia extrema y pérdida de la consciencia, siendo automáticamente corregible con el uso de mascarillas que suministran oxígeno al $100 \%$ que, mientras desciende el avión, protegen de la hipoxia hipobárica. Por encima de los 12.000 m.s.n.m. la saturación de oxígeno disminuye rápidamente hasta aproximadamente el 50\% ( 14.300 m.s.n.m.). Otros modelos de aviones de combate más moderno, como los aviones supersónicos, realizan vuelos por encima de los 12.000 m.s.n.m., donde una despresurización a esa altura ocasiona una rápida pérdida de la conciencia, lo que obliga por seguridad el uso permanente del equipo de respiración a presión que suministra oxígeno a $40 \mathrm{cmH} 2 \mathrm{O}^{23}$.

El uso de instrumentos de grabación y de una cámara de Cine en el avión supuso un avance para probar y registrar movimientos previos que impidiesen o favoreciesen el retraso de la inconsciencia. Desde el minuto 52 (52':00"), médico y piloto replican juntos (a) caídas en picado, (b) pruebas de túnel de velocidad, y (c) remontadas $a+9 \mathrm{G}$, con indicaciones del instructor del ensayo pidiendo que en la primera remontada se tensen los músculos de la cabeza a los pies, apretando al máximo el vientre y gritando con todas las fuerzas para comprobar si esta actuación evita el desvanecimiento. Las grabaciones indicaban que gritar no servía de nada cuando se remontaba tras la realización de un picado a diferentes alturas estabilizadas (4.500 m.s.n.m. -1.500 m.s.n.m.). En todo caso el desmayo era más leve y se despertaba en segundos, pero no era efectivo (Foto 4). El azar quiso que el médico de vuelo no se desmayara al

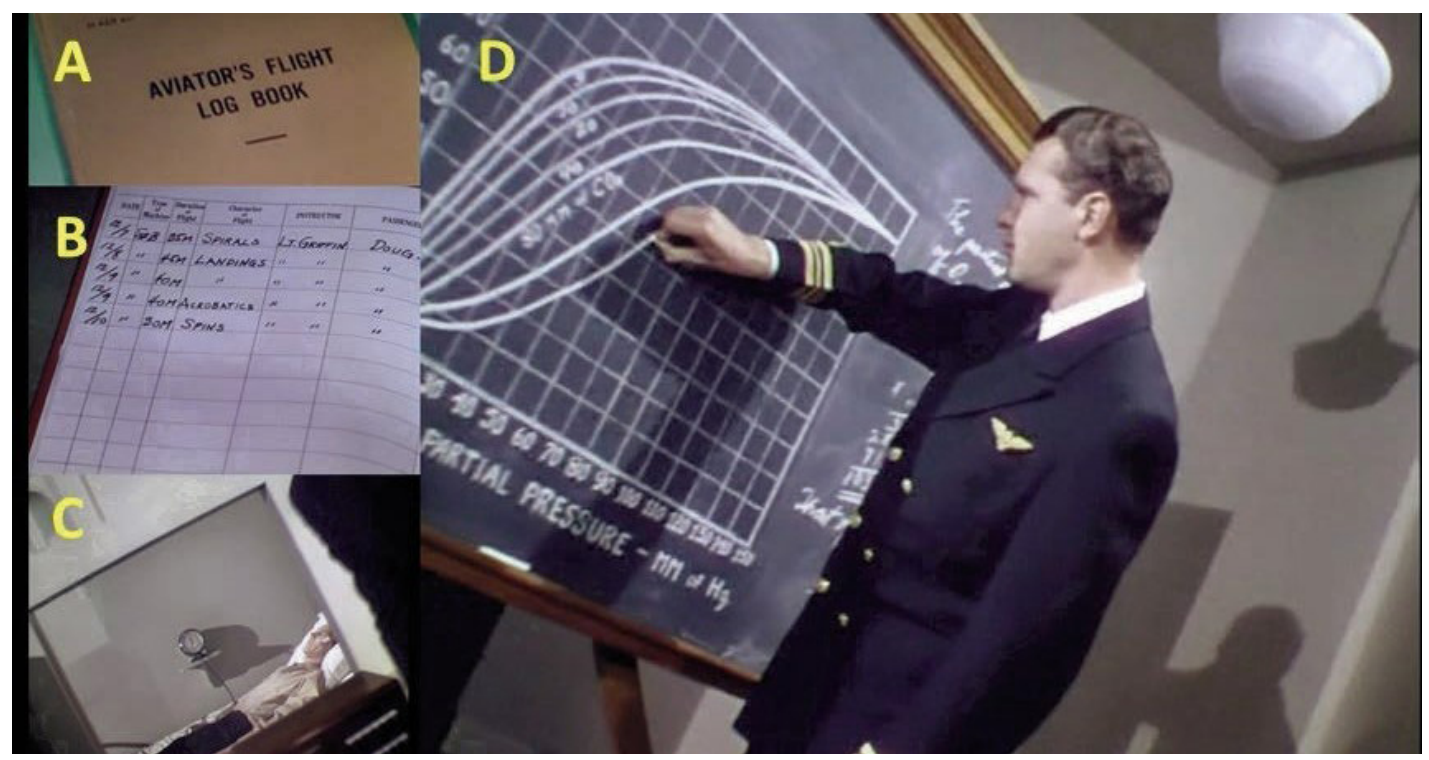

Foto 3. Ejercicios prácticos para el entrenamiento del aviador apuntados en el libro de vuelo del piloto (A-B), prueba de ejercicio hipobárico (C) y medición de la curva de disociación de la hemoglobina por el efecto Bohr (D).

Rev. Med. Cine. 2020; 16(4), 261-277 Ediciones Universidad de Salamanca / 


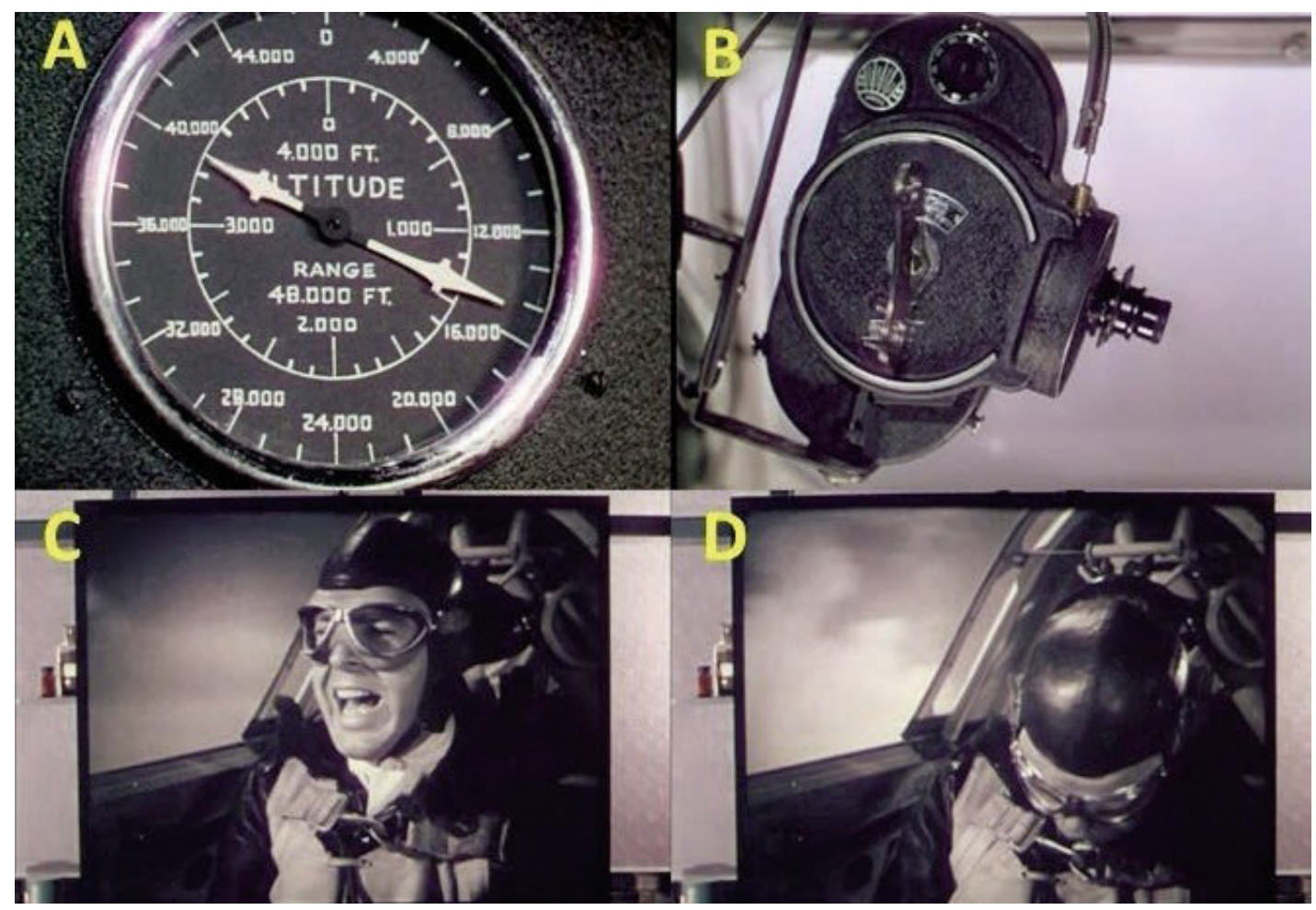

Foto 4. Las imágenes grabadas dentro de la carlinga mostraban que gritar durante la remontada, a 4.500 m.s.n.m. (14.763,76 pies) después de una picada, no evitaba el desmayo.

cambiar su posición postural tras inclinarse para arreglar el atasco de la cámara al instante de la remontada durante la picada. El doctor se encontraba en ese momento inclinado con el corazón a la altura del cerebro y la sangre quedaba a la altura del corazón, evitando el desmayo, pero no evitaba la aparición de mareo. Actualmente esta es una técnica de protección del cuerpo contra el colapso circulatorio que se podría producir durante la G+. Si el aviador tensa los músculos abdominales hasta un grado extremo y se inclina hacia delante para comprimir el abdomen, se puede evitar parte de la acumulación de sangre en los grandes vasos del abdomen, retrasando de esta manera el inicio del síncope del piloto ${ }^{24}$.

En la década de los 40, el Dr. Wilbur Franks inventó el primer traje anti-G, denominado traje de vuelo de Frank, siendo el primer modelo que evitaba la pérdida de la conciencia por las fuerzas G (G-LOC), hasta $+9 \mathrm{G}$ en los trajes de combate moderno, actuando directamente sobre la prevención y/o tratamiento de la hipotensión ortostática ${ }^{25}$. En el film ese momento se refleja en el minuto 60 (60':17'), donde el nacimiento de ese mismo traje surge del chiste jocoso de un piloto, asegurando que un cuello duro que ahogara al piloto evitaría que la sangre bajara del cerebro. Justo en ese momento obtienen como respuesta el uso de un cinturón neumático, a modo de corsé, que al iniciar el picado se inflara y presionara el estómago, bajo las costillas, comprimiendo toda la región abdominal y favoreciendo que la sangre quede por encima del corazón (Foto 5 , A-D). A continuación (61':21') el médico prueba Rev. Med. Cine. 2020; 16(4), 261-277 Ediciones Universidad de Salamanca / @®@@

J. Med. Mov., 2020; 16(4), 261-277 


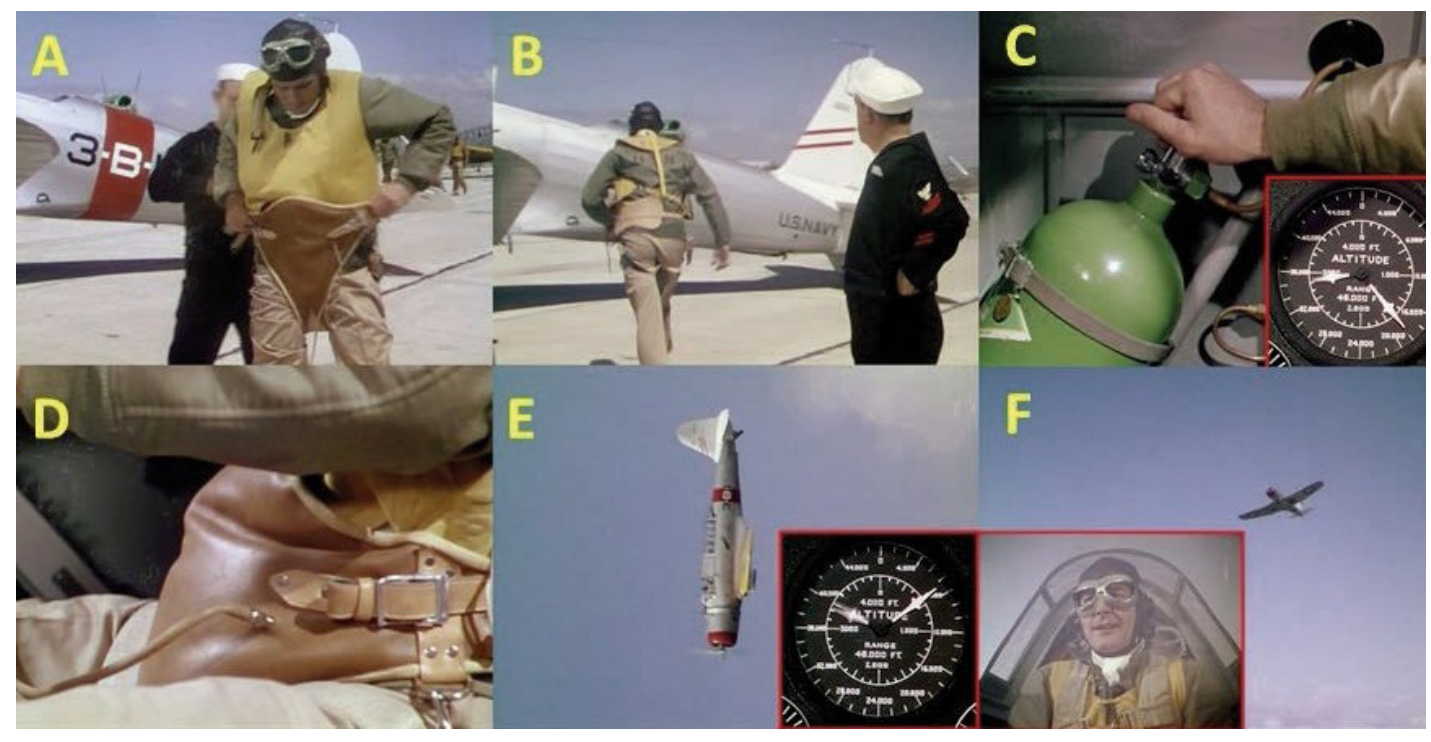

Foto 5. (A-B) Prueba de ensayo del primer traje anti-G durante un vuelo en picada. (C-D) A $~ 5.791$ m.s.n.m. ( 19.000 pies) se inicia el picado y se abre la válvula de aire comprimido para inflar el cinturón neumático.

(E-F) Durante la remontada a 2.438 m.s.n.m. ( 8.000 pies), se consigue evitar el desmayo.

con éxito el traje experimental, enganchando al corsé una bombona de aire comprimido de la cabina. Al momento del inicio del picado el piloto abre la válvula y se infla el traje, ayudando a la compresión de los vasos sanguíneos. A la salida del picado no se observaron mareos ni padecimiento de síncope (Foto 5, E y F). Esta prueba solucionó los problemas de desmayos y quedó aprobado por Washington la autorización de estos modelos de cinturones.

\section{Capacidad de atención y aptitud física}

Para el estudio de procesos cognitivos que afectan a la atención se realizan una serie de pruebas que miden y mejoran la cantidad de tiempo concentrado que una persona puede dedicar a una tarea sin distraerse. Uno de los ejercicios se realiza con simuladores de aviones para pilotar vuelos a ciegas. Durante el minuto $40\left(40^{\prime}: 18^{\prime \prime}\right)$, una de las indicaciones del médico instructor es no fiarse de los sentidos sino de los instrumentos de vuelo, debido a que los conductos auditivos dan una sensación engañosa de la orientación (Foto 6). Más adelante (45':17'), se propone usar la prueba del test de Rorschach (análisis de manchas de tinta) para determinar características de personalidad (problema psicológico y estado psíquico) y funcionamiento emocional (de ánimo y de fatiga) del personal de aviación a través de una serie de pruebas proyectivas ${ }^{26-28}$. Todos esos pilotos que no superaban los tests psicológicos eran retirados de sus servicios por presentar estadios transitorios de enajenación mental, un término incorrecto que cambió de nombre en la década de los 90 tras la guerra del Vietnam, pasando a llamarse estrés postraumático ${ }^{29,30}$. Otras pruebas complementarias que se realizan son las de orientación y de reacción de mareo (58':18'), situando al piloto sobre una silla giratoria y el médico acciona una manivela que activa un mecanismo de rotación sobre su mismo eje (Foto 6). 


\section{BOMBARDEROS EN PICADO (1941): UN MODELO DE ESTUDIO DE LA FISIOLOGÍA DE LA AVIACIÓN GERMÁN DOMÍNGUEZ-VÍAS}

Junto con las pruebas anteriores, se realizan nuevas pruebas que determinan si el piloto puede seguir volando a través de la detección de cambios de pulsaciones y la tensión arterial. Entre ellas se encuentra el sistema de valoración cardiovascular o prueba de Schneider ${ }^{31}$. Schneider describió un método para evaluar la aptitud física en 1920, empleando seis conjuntos de observaciones: (a) frecuencia del pulso en la posición reclinada; (b) frecuencia de pulso de pie; (c) el aumento en la frecuencia del pulso cuando se comparan las frecuencias de pie y reclinada; (d) el aumento en la frecuencia del pulso después del ejercicio estándar; (e) el tiempo requerido para que la frecuencia cardíaca regrese a la frecuencia cardíaca después del ejercicio; y (f) el cambio en la presión arterial sistólica cuando el examinado se pone de pie. Esta prueba se emplea como un indicio general de la aptitud física y para dar una idea de la capacidad del corazón para adaptarse a una mayor exigencia del sistema circulatorio, de esta manera, certifica la presencia o ausencia de «fatiga de pilotos». En el minuto $70\left(70^{\prime}: 10^{\prime \prime}\right)$, uno de los médicos de la base militar de San Diego (EE.UU.) prohíbe volar a uno de sus pilotos por la cronificación de la fatiga. El médico señala la evolución desfavorable de su gráfica (en rojo), mostrando los puntos decisivos de irritabilidad, estrés y baja forma, por lo que recomienda dejar de volar un tiempo prolongado (2 meses) o incluso nunca (Foto 7).

\section{Hipobarismo}

El uso del cinturón neumático demostró evitar los desmayos, pero originaba otro tipo de consecuencias debido a la altitud, la hipoxia y la descompresión de nitrógeno en las alturas a 7.000 m.s.n.m. Estudiar como subir al avión a un piloto desnitrogenado era una causa casi imposible, pero si era posible reproducir y evaluar las condiciones de vuelo de baja presión por altitudes elevadas con la ayuda de una cabina hipobárica. La activación de una bomba (Foto 8A) para extraer el aire y disminuir la presión atmosférica dentro de una cámara con animales y/o humanos (Foto 8 , B y D-I), facilitaban la simulación de estas condiciones ambientales en relación a la altitud, hasta 12.000 m.s.n.m. como límite (Foto 8, Cy E). El ajuste de oxímetros al oído ayudaba a monitorizar cuanto oxígeno hay en sangre (Foto 8G). A mayor altitud, mayor torpeza para coordinar las maniobras de vuelo de forma adecuada. Esto se muestra mediante un ejercicio (75':00') donde los pilotos deben seguir el movimiento de una luz sobre un panel, con la ayuda de los controles mientras ascienden (Foto

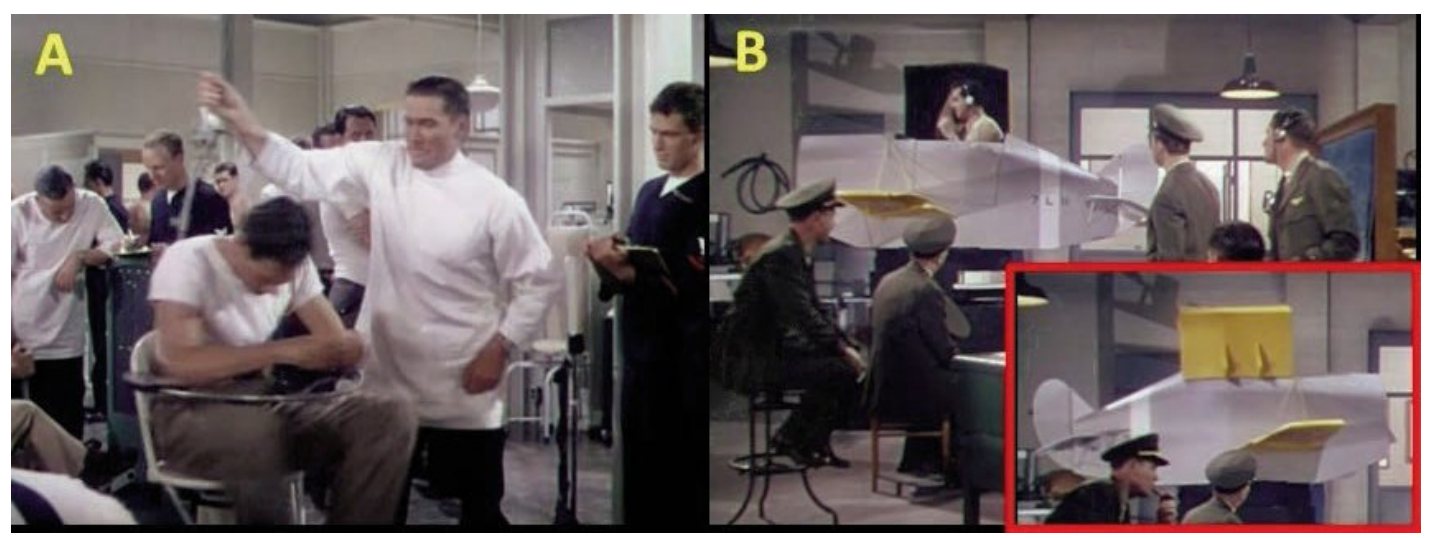

Foto 6. Pruebas de mareo (A) y atención (B) del simulador de vuelo.

Rev. Med. Cine. 2020; 16(4), 261-277 Ediciones Universidad de Salamanca / 
$8 \mathrm{H})$. Una luz verde muestra la capacidad de coordinación. A continuación, se enumera todos los intervalos crecientes a los que fueron sometidos (en m.s.n.m.): 1.500, 1.800, 2.100, 2.400, 2.700, $3.000,3.300$, 3.600 (se colocan un grupo de pilotos de prueba las máscaras de oxígeno; Foto 81), 3.900, 4.800, 5.700, 6.000, 6.400 (aparecen efectos de hipoxia hipobárica en pilotos que decidieron no colocarse la máscara de oxígeno; Foto 9A), 6.700 (visión desenfocada de las luces y pérdida de la coordinación. Caída de la aguja a la zona roja por debajo del $50 \%$ del techo de saturación de oxígeno en sangre arterial, con un desmayo inminente. La implementación de oxigenoterapia sale de la zona roja y restaura rápidamente la saturación de oxígeno en sangre arterial por encima del $50 \%$; Foto 9, B-E), 7.300, 7.600, 8.200, 8.500, $8.800,9.000,9.300,9.600$ (presencia de hipoxia

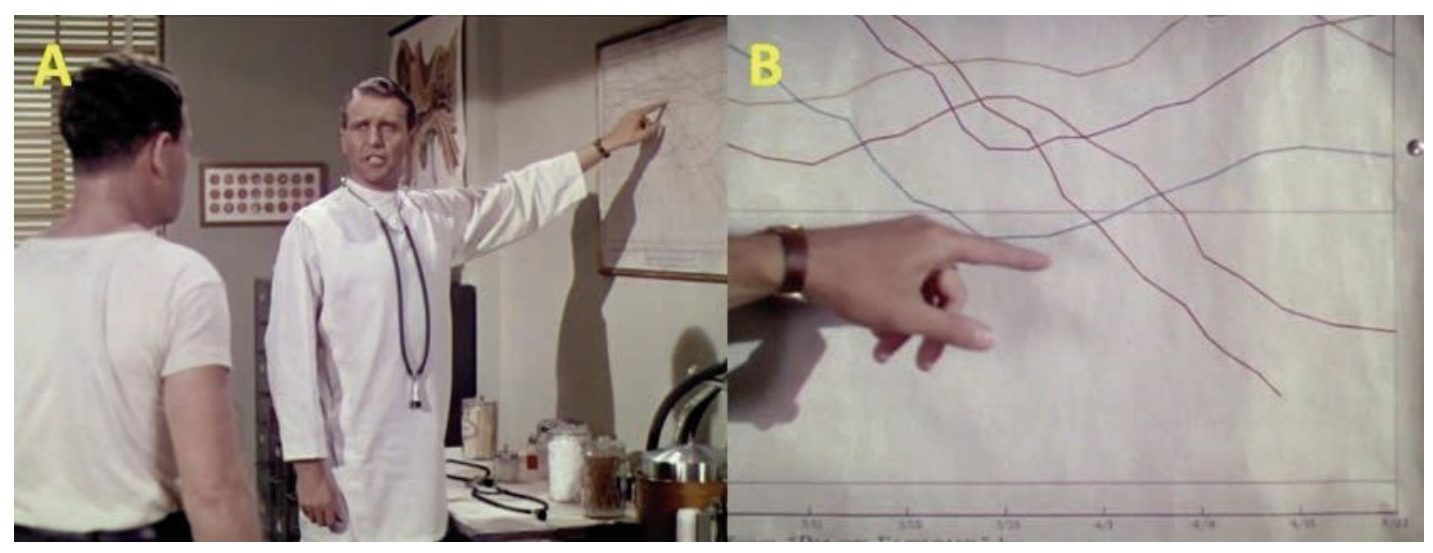

Foto 7. Gráfico de índice de Schneider en un caso de un piloto que presenta el punto crítico de la línea de «fatiga de piloto».

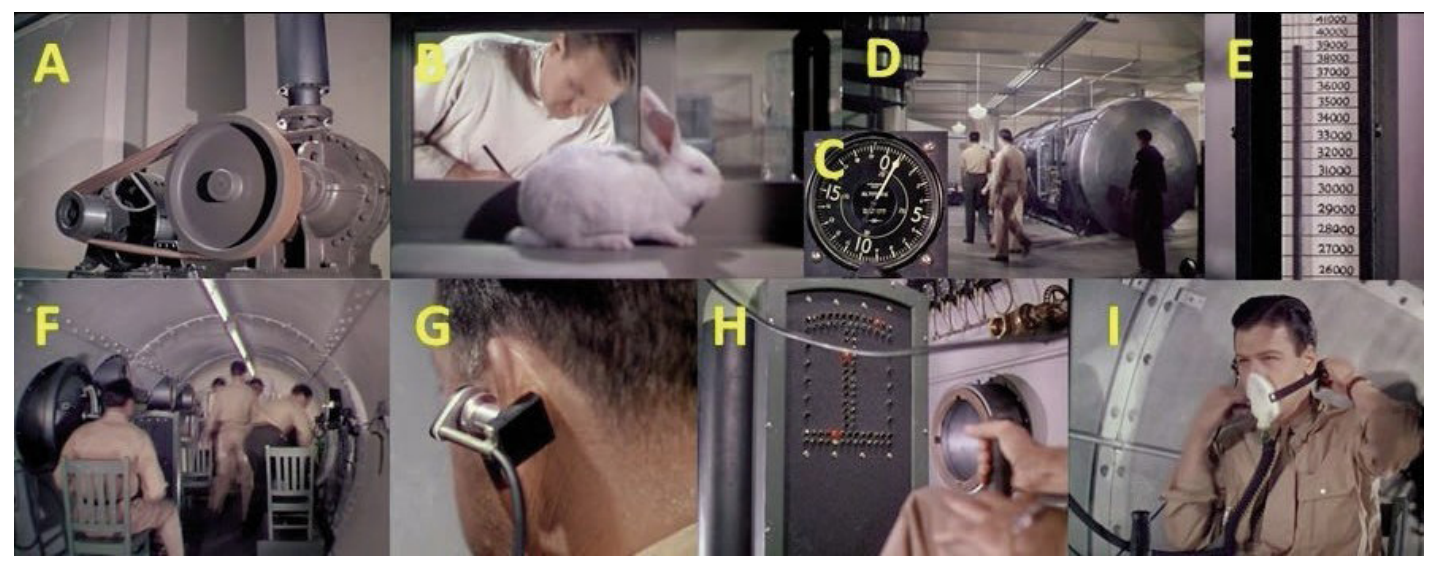

Foto 8. Experimentos de hipoxia hipobárica en animales (B) y humanos (D-I) con el propósito de estudiar cómo afecta la falta de oxígeno a la capacidad para coordinar movimientos. Una bomba extrae el aire $(A)$ de la cámara para simular las condiciones de baja presión atmosférica en el ascenso, hasta alcanzar los 12.000 m.s.n.m. (39.370 pies; E).

Rev. Med. Cine. 2020; 16(4), 261-277 Ediciones Universidad de Salamanca /

요@( Med. Mov., 2020; 16(4), 261-277 


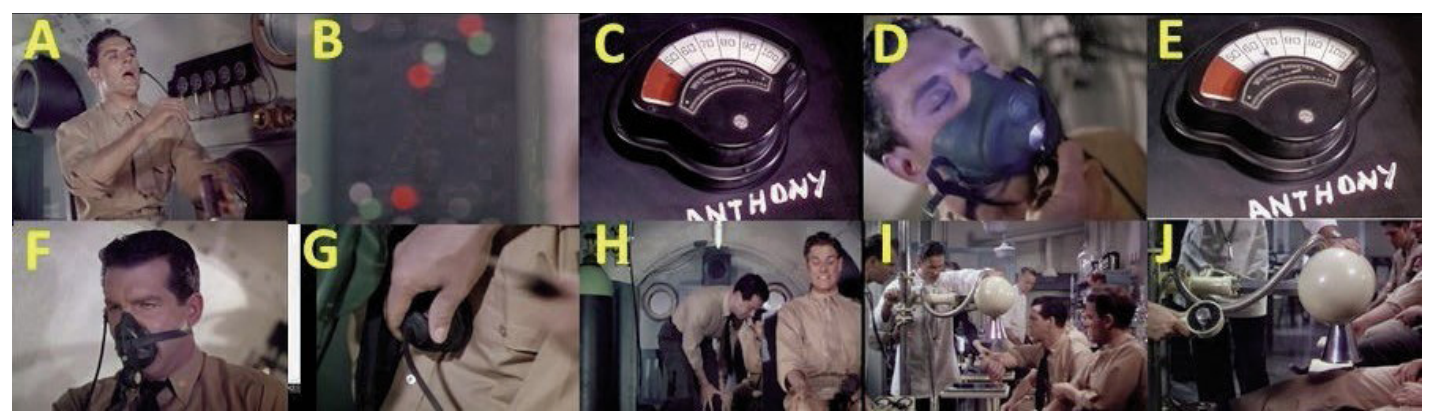

Foto 9. (A-C) Por debajo del techo de la saturación de oxígeno en sangre arterial $(<50 \%)$, el piloto pierde el conocimiento. (D-E) La oxigenoterapia restablece la recuperación del conocimiento y de la saturación de oxígeno en la hemoglobina por encima del 50\%. (F-G) Los efectos de la cianosis ralentizan el ritmo cardiaco.

$(\mathrm{H}-\mathrm{J})$ Las pruebas radiológicas demuestran que a mayor altura puede favorecer la aparición de émbolos por la enfermedad de la descompresión en las articulaciones.

con caras cianóticas, la aguja baja de $60 \%$ bruscamente; Foto 9F), 10.600 (apertura al máximo de la válvula de oxígeno y desaparece la cianosis. Razonan que la causa de ese problema es por un error de cálculo, al estar mal ajustado para una persona de su complexión), 10.900, 11.200, $\sim 12.000$ (auscultan los ruidos cardiacos; Foto 9G). Al estar todos cianóticos, advierten que sus ritmos cardiacos son mucho más lentos que el de una persona con suficiente oxígeno), 12.000, fin de la prueba. A 12.000 m.s.n.m. paran la ascensión y estudian cuanto tiempo son capaces de soportar a esta presión, observándose a todos sufriendo de hipoxia e hipoxemia (valores de saturación muy por debajo del 50\%). Terminada la prueba reducen la altura (aumenta la presión) de forma repentina y se advierte de tener cuidado con los oídos. En el minuto $90\left(90^{\prime}: 50^{\prime \prime}\right)$, uno de los pilotos manifiesta una embolia en la región de la rodilla (Foto 9H). El médico masajeaba la zona dolorida y frotaba fuerte para reactivar el flujo sanguíneo, indicando como si en su circulación tuviese gelatina. Las pruebas radiológicas en articulaciones del codo y rodilla (Foto 9, I-J) demostraron indicios de formación de burbujas solo en las rodillas. Las pruebas relacionaban de forma contundente que, a más altitud, más problemas de enfermedades de descompresión repentina ocurrían, siendo su única terapia el uso de cámaras hiperbáricas ${ }^{32-34}$. Esta enfermedad de descompresión con la disminución de la presión barométrica causa la formación de burbujas in situ a partir de gas inerte disuelto y embolia gaseosa arterial, en la cual el gas alveolar o la embolia de gas venoso (a través de derivaciones o derivando a vasos pulmonares) se introducen en la circulación arterial ${ }^{35}$.

Para evitar la enfermedad de la descompresión debaten (91':56") la posibilidad de restringir los vuelos a 10.600 m.s.n.m. siendo el límite, pero los militares rebaten que un caza aliado debe de ponerse por encima de los demás cazas enemigos sin restringir la altitud. Es por ello que empiezan a estudiar un nuevo objetivo, hallar las causas de los mareos a altitudes elevadas y comprobar si es por la falta de oxígeno o la formación de burbujas. Se conocía que los pilotos necesitaban oxígeno por encima de los 3.600 m.s.n.m. y desconocían las causas que producían los mareos, pero sí como evitarlos haciendo que los pilotos estén siempre a la misma presión que a la altura del nivel mar $(760 \mathrm{mmHg})^{1}$ por mucho que suban los pilotos con la ayuda de cabinas presurizadas. Además, el peso de una cabina presurizada le haría ascender 1.500 m.s.n.m. menos en un caza, siendo ideal para aviones grandes donde el peso no importa tanto. 
Para paliar estos problemas de salud por despresurización se planteó el uso de cabinas presurizadas o la necesidad de un traje presurizado $\left(92^{\prime}: 33^{\prime \prime}\right)$, para que estén siempre a la misma presión que al nivel del mar, sin analogías a una armadura por la dificultad que conllevaría el movimiento. Además, el traje debería tener articulaciones flexibles, con cierta similitud al diseño de los trajes de los buzos con escafandra, y con la capacidad de retener oxígeno en su interior. Sin embargo, la prueba experimental con la cabina presurizada fue un fracaso y estuvo a punto de ocasionar la muerte de los protagonistas. La cabina disponía de válvulas que regulaban el oxígeno, la temperatura y la presión barométrica dentro de todo el avión, pero no se pensó que, a 10.600 m.s.n.m., por efecto de la hipotermia asociada a la altura, la humedad se condensaría (Foto $10 \mathrm{C}$ ) y congelarían los reguladores de las válvulas (Foto 10, A-D), no pudiendo equilibrar per se ni la temperatura, ni la humedad, y congelando el anticongelante y los controles de mando, imposibilitando el hielo el vuelo dejándolo sin respuesta y completamente inservibles. Todo ello, junto a la hipoxia hipobárica, provocó un cuadro de cianosis seguido del síncope de uno de los pilotos. La rápida intervención del médico a los mandos del avión y su asistencia con máscaras de oxígeno evitó que se estrellaran.

El infructuoso resultado anterior dio lugar a experimentar con la armadura presurizada, cuyo diseño se asemeja a los trajes aeroespaciales modernos (Foto 10, E y F). La prueba con el traje es completamente funcional en la cámara hipobárica tras simular alturas superiores de 12.000 m.s.n.m. $\left(112^{\prime}: 31^{\prime \prime}\right)$, parando la prueba a 13.700 m.s.n.m. La prueba real dentro de un avión demostró que el traje era completamente funcional (Foto 10G). A partir de 10.000 m.s.n.m. el traje funcionaba correctamente y era viable la regulación de más

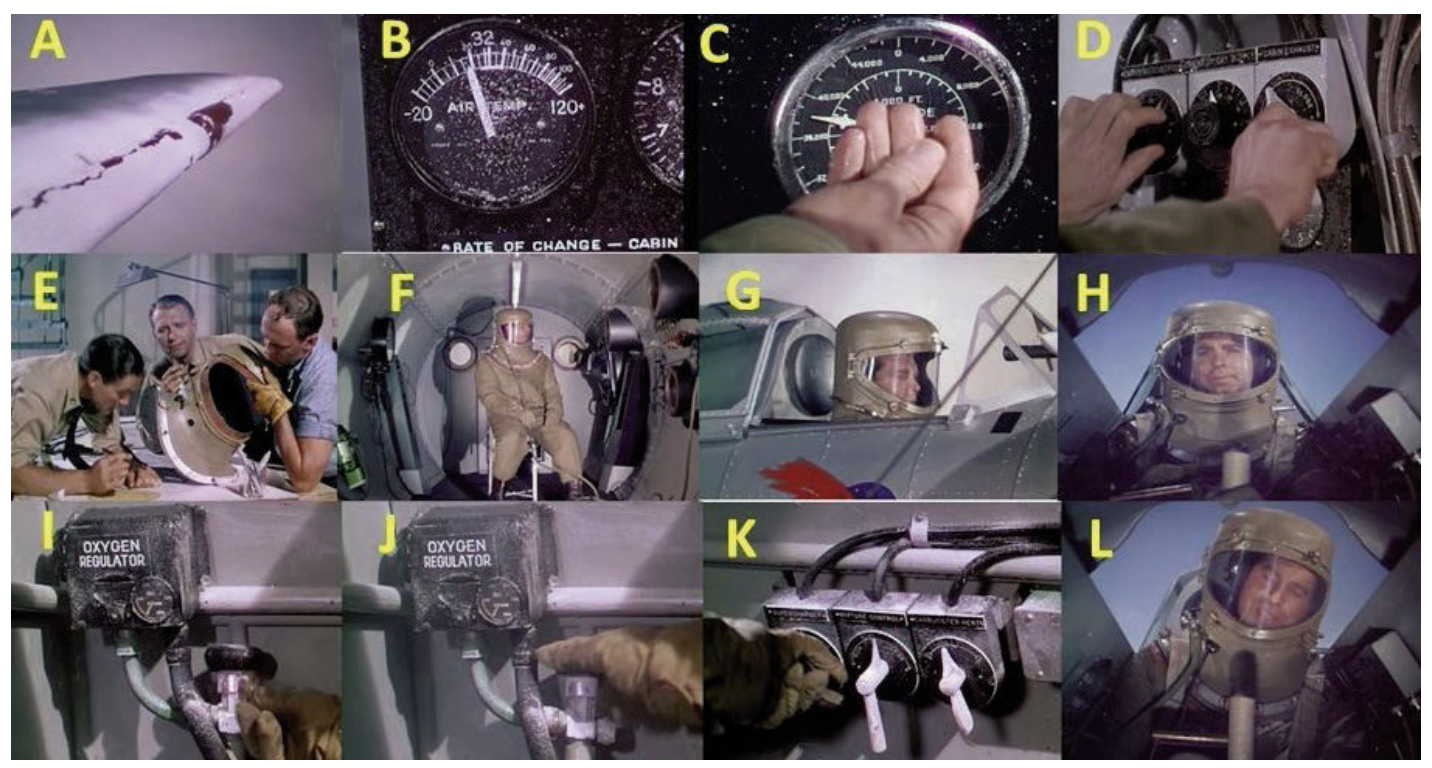

Foto 10. (A-D) Las pruebas con un avión presurizado fue un fracaso por congelarse la dirección y todo el equipo, ocasionando el síncope en uno de los pilotos. (E-F) Diseño de un traje presurizado y prueba en cámara hipobárica. (G-L) Prueba real del traje presurizado siendo funcional, pero con un desenlace fatal para el piloto por congelarse el regulador de oxígeno.

Rev. Med. Cine. 2020; 16(4), 261-277 Ediciones Universidad de Salamanca / 


\section{BOMBARDEROS EN PICADO (1941): UN MODELO DE ESTUDIO DE LA FISIOLOGÍA DE LA AVIACIÓN GERMÁN DOMÍNGUEZ-VÍAS}

oxígeno, a pesar de encontrar indicios de congelación en las válvulas reguladoras de oxígeno y altímetro, a lo que el piloto advierte, antes de morir, que se deben añadir futuras mejoras al traje como mecanismos que calentaran el tubo de oxígeno para evitar el hielo; de esta manera se conseguiría la perfección en el traje presurizado (Foto 10, G-L). Es probable que la causa de este síncope sea, como ocurren con los trajes de buzo, una mala ventilación por el déficit de $\mathrm{PO}_{2}$ y la acumulación de los niveles de dióxido de carbono acumulado, causando hipoxia y efectos de somnolencia. Al final de la película se muestra como la versión mejorada de este traje fue evaluado en un vuelo con pilotos de prueba y aprobado por el ejército de EE.UU.

\section{Resultados y discusión}

Este trabajo detalla una de las películas más exactas en la descripción de las alteraciones fisiológicas producidas por un ambiente hipobárico. Durante la contienda de la Segunda Guerra Mundial, los pilotos de prueba buscaban conseguir, a contrarreloj, las contramedidas que evitasen el fallecimiento de más pilotos por la dureza del ambiente físico que por la propia batalla ${ }^{5,12}$. El estudio de la fisiología en situaciones especiales para recuperar la homeostasis corporal era un gran desafío, y se sabía que solucionar ese problema daría una ventaja para ganar la guerra. A día de hoy esas hazañas se han hecho ya casi rutinarias, y se conoce mejor el comportamiento fisiológico ante la adaptación del organismo a condiciones adversas. Para un aviador son importantes los cambios fisiológicos motivados por las diferencias en la presión y en la cantidad de oxígeno ambiental, en las temperaturas extremas y también, en el caso de maniobras con giros, acrobacias y picadas, por las aceleraciones e ingravidez ${ }^{19,22,34}$.

Esta película como modelo audiovisual es interesante por aportar datos que complementarían la enseñanza-aprendizaje en el temario de (a) la anatomía por traumas severos tras estrellarse por el síncope, y (b) la fisiología a grandes alturas y vuelos aeronáuticos, ofreciendo gran cantidad de detalles simulados de problemas médicos relacionados con la exposición a la altitud, como determinante de los factores altitud, la velocidad (de ascenso/descenso) y la duración de la exposición. También es observable en la película que se consideran otros factores no relacionados con la altura, el nivel de ejercicio desarrollado (pruebas físicas), el comportamiento psicológico, la susceptibilidad fisiológica individual, además de la edad del piloto que se ofrece a las pruebas. La razón de que los pilotos de prueba tengan distintos comportamientos dentro de la cámara hipobárica es en función de todos estos factores, variando en frecuencia de aparición (de raros a comunes) y en intensidad mediante gráficas de líneas que delimitan si son benignos y autolimitados o evolucionan rápidamente hasta convertirse en una fatiga, imposibilitando al piloto continuar las pruebas hasta su recuperación (en el caso de que sea reversible). Todas estas alteraciones y estados de estrés, o una continua acumulación de estos factores, son ocasionados por el mal de altura (enfermedad aguda de altura), dando origen a edemas de altitud inducidas por hipoxia ${ }^{1}$, en concreto la aparición de edema pulmonar, el edema cerebral y/o el edema periférico. Gran parte de los pilotos que ascienden a elevada altitud presentaban cambios ventilatorios ${ }^{22}$, cardiovasculares en su presión arterial, frecuencia cardiaca, y en la señal eléctrica del corazón ${ }^{20,24}$, además de cambios funcionales hepáticos y otras alteraciones metabólicas ${ }^{21}$. Por un lado, parece tener relación la inducción de la hipoxia con la aparición de estos edemas por retención de sodio y agua ${ }^{1}$. También puede ocurrir por problemas tromboembólicos por descompresión, accidentes isquémicos, trombosis venosa profunda, policitemia inducida por hipoxia, anormalidades de coagulación, deshidratación, congelación, y/o estasis venosa por periodos prolongados sentado durante largas horas de vuelo ${ }^{36,37}$. 
Las pruebas médicas realizadas a los pilotos de este film transcurren a la misma altura que los actuales vuelos comerciales, entre 9.000 - 12.000 m.s.n.m., con las ventajas de ahorro de combustible que supone y por poseer una mayor estabilidad climática a esas alturas. En esa época todavía no era habitual el uso de aviones con cabinas y trajes presurizados. Un modelo experimental que desarrollan en el largometraje, para evitar el desmayo en las alturas, consisten justo en la prueba de una de esas cabinas. A pesar de no dar un resultado positivo en la experimentación, actualmente todos los modelos de aeronaves comerciales si han desarrollado, y mejorado, ese sistema, por lo que la cabina debe estar presurizada con unas presiones internas equivalentes a las de altitudes inferiores a 2.400 m.s.n.m., lo que se denomina "altitud de cabina». La diferencia de presión entre el exterior y el interior no es constante, en la práctica, y se incrementa conforme el avión sube a mayor altitud. Lo habitual es que la altitud de cabina no supere los 2.000 m.s.n.m., lo que corresponde a presiones superiores a $600 \mathrm{mmHg}$ y un porcentaje de oxígeno equivalente al nivel del mar. En condiciones fisiológicas, estos valores ocasionan una discreta disminución de la saturación de oxígeno y mínimos cambios fisiológicos. Sin embargo, puede ser peligroso para pacientes con insuficiencia respiratoria que presenten una $\mathrm{PO}_{2}$ por debajo de $70 \mathrm{mmHg}$, a no ser que sean tratados con oxígeno suplementario $^{38,39}$.

Un aspecto muy logrado de esta película es el fenómeno de la gravedad desde el punto de vista de la fisiología, caracterizando a los personajes que alcanzan $\mathrm{G}+$ de magnitudes considerables durante las picadas, considerando positivas las fuerzas que presionan al individuo contra el asiento y la sangre hacia los pies, llegando a ocasionar ceguera transitoria e incluso lesiones durante tiempos prolongados, afectando de forma importante esta característica móvil de la sangre por las fuerzas centrífugas a la parte inferior del organismo, aumentando la presión hidrostática en las venas de los pies (con aparición de edemas), una disminución del retorno venoso y, por ende, del gasto cardiaco, traduciéndose en hipotensión arterial, mareo, pérdida de la conciencia, e incluso muerte o fracturas y lesiones medulares si persiste la aceleración. El desarrollo de los trajes anti gravitatorios o anti-G fue un gran logro en la película y en la realidad, disminuyendo el desplazamiento de la sangre por compresión neumática, a medida que aumentan las aceleraciones, hacia las zonas inferiores y evitando el acúmulo de sangre en pierna y abdomen.

\section{Conclusiones}

Bombarderos en picado supone un recurso docente para el profesorado que quiera transmitir de forma muy acertada conceptos de la adaptación medioambiental en la fisiología de la aviación. Todos los casos clínicos y experimentales del film se basan en hechos reales y relatan de forma fidedigna el recorrido del método científico hasta dar respuestas a todas las incógnitas que desencadenaban el estrellamiento del avión y la muerte o paraplejia del piloto por alteraciones anatómicas.

\section{Agradecimientos}

El Dr. Domínguez-Vías agradece al profesor Dr. José Juan Vallo de Castro, del área de fisiología de la universidad de Cádiz, por sembrar la valiosa semilla del conocimiento en la fisiología de la aviación.

\section{Referencias}

1. Domínguez-Vías G. The Disaster of 96: An educational way of explaining the physiological reactions produced as a consequence of exposure to low oxygen pressure at high altitude using the film Everest (2015). J Med Mov [Internet]. 2018;14(4):227-36.

2. Shin YH, Yun C, Han AH. Cervical spine status of pilots and air-controllers of air-borne early warning and control aircraft. Aerosp Med Hum Perform. 2017;88(5):476-80. 


\section{BOMBARDEROS EN PICADO (1941): UN MODELO DE ESTUDIO DE LA FISIOLOGÍA DE LA AVIACIÓN GERMÁN DOMÍNGUEZ-VÍAS}

3. Martín-Ferrer S. Traumatismos de la columna cervical alta: Clasificación tipológica, indicaciones terapéuticas y abordajes quirúrgicos (a propósito de 286 casos). Neurocirugia. 2006;17(5):391-419.

4. Morales-Avalos R, Villarreal-Garcia FI, RequenaAraujo PM, Guzmán-López S, Sanchez-Mejorada G, Esparza-Hernandez CN, et al. Anatomía Morfométrica de Importancia Clínica del Atlas en Relación a la Estabilización del Complejo Atlantoaxial y Occipitocervical. Int J Morphol. 2019;37(1):98-103.

5. Ly C, Yusof MPM, Hasmi A, Mahmood M. Death of two military pilots in Hawk- 108 fighter jet crash. J Forensic Sci Med. 2018;4(2):101.

6. Wiegmann DA, Taneja N. Analysis of injuries among pilots involved in fatal general aviation airplane accidents. Accid Anal Prev. 2003;35(4):571-7.

7. Gonzalez L. Technique for fixating the atlantooccipital complex with a transarticular screw. Spine (Phila Pa 1976). 2002;27:219-20.

8. Grob D. Transarticular Screw Fixation for Atlanto-Occipital Dislocation. Spine (Phila Pa 1976). 2001;26(6):703-7.

9. Jefferson G. Fracture of the atlas vertebra. Report of four cases, and a review of those previously recorded. Br J Surg. 1919;7(27):407-22.

10. Martin-Ferrer S, Rimbau J, Joly MC, Teruel J, Pont J. Fracturas de la apofisis odontoides: Revision de nuestra casuistica, implicaciones terapeuticas y nueva clasificacion. Neurocirugia. 1999;10(6):426-38.

11. Martín Ferrer S, Rimbau Muñoz J, Feliu Tatay R. Atornillado anterior en las fracturas agudas de la odontoides. Neurocirugia. 1996;7(2):89-99.

12. Adams VI. Neck Injuries: II. Atlantoaxial Dislocation. A Pathologic Study of 14 Traffic Fatalities. J Forensic Sci. 1992;37(2):13263J.

13. Bachs A, Barraquer-Bordas $L$, Barraquer-Ferré $L$, Canadell J, Modolell A. Delayed myelopathy following atlanto-axial dislocation by separated odontoid proces. Brain. 1958;78(4):537-53.

14. Crockard HA, Heilman AE, Stevens JM. Progressive myelopathy secondary to odontoid fractures: Clinical, radiological, and surgical features. J Neurosurg. 1993;78(4):579-86.
15. Miller C, Boulter J, Coughlin D, Rosner M, Neal C, Dirks M. Return-to-active-duty rates after anterior cervical spine surgery in military pilots. Neurosurg Focus. 2018;45(6):E10.

16. Hadley M, Walters B, Grabb P, Oyesiku N, Przybylski G, Resnick D, et al. Management of Combination Fractures of the Atlas and Axis in Adults. Neurosurgery. 2002;50(suppl_3):S140-7.

17. Yoon DH, Yang KH, Kim KN, Oh SH. Posterior atlantoaxial dislocation without fracture: Case report. J Neurosurg. 2003;98(1 Suppl):73-6.

18. Tolga Aydoğ S, Türbedar E, Demi rel AH, Tetïk O, Akin A, Doral MN. Cervical and Lumbar Spinal Changes Diagnosed in Four-View Radiographs of 732 Military Pilots. Aviat Space Environ Med. 2004;75(2):154-7.

19. Scott JM, Esch BTA, Goodman LS, Bredin SSD, Haykowsky MJ, Warburton DE. Cardiovascular consequences of high-performance aircraft maneuvers: Implications for effective countermeasures and laboratory-based simulations. Appl Physiol Nutr Metab. 2007;32(2):332-9.

20. Comens P, Reed D, Mette M. Physiologic responses of pilots flying high-performance aircraft. Aviat Space Environ Med. 1987;58(3):205-10.

21. Shi B, Wang XQ, Duan WD, Tan GD, Gao HJ, Pan $\mathrm{YW}$, et al. Effects of positive acceleration (+Gz stress) on liver enzymes, energy metabolism, and liver histology in rats. World J Gastroenterol. 2019;25(3):346-55.

22. Harding RM, Mills FJ. Aviation medicine. Problems of altitude I: hypoxia and hyperventilation. Br Med J (Clin Res Ed). 1983;286(6375):1408-10.

23. Inoriza JM, Estanyol N, Robert M, Galán R, Villalonga A. Fisiología en situaciones especiales: buceo, grandes alturas y vuelos aeronáuticos y espaciales. In: CEEA/ESA, editors. Fisiología aplicada a la Anestesiología. Madrid: Ergon; 2012. p. 417-27.

24. Figueroa JJ, Basford JR, Low PA. Preventing and treating orthostatic hypotension: As easy as A, B, C. Cleve Clin J Med. 2010;77(5):298-306.

25. Hoepfner M, Schultz M, Schultz J. Libelle Self-Contained Anti-G Ensemble: Overcoming Negative Transfer. J Aviat Educ Res. 2004; 13(2):21-34.

26. Guerrier S. Man on the moon. The Lancet Psychiatry 2019;6(7):570-2.

Rev. Med. Cine. 2020; 16(4), 261-277 Ediciones Universidad de Salamanca / @@ J. Med. Mov., 2020; 16(4), 261-277 


\section{BOMBARDEROS EN PICADO (1941): UN MODELO DE ESTUDIO DE LA FISIOLOGÍA DE LA AVIACIÓN GERMÁN DOMÍNGUEZ-VÍAS}

27. Shanker M. Recruitment process and its impact on retention of commercial pilots in Indian aviation industry. Bus Process Manag J. 2019.

28. Shayler DJ, Burgess C. The selections, Chapter 1. In: Shayler DJ, Burgess C, editors. The Last of NASA's Original Pilot Astronauts: Expanding the Space Frontier in the Late Sixties. Cham, Switzerland: Springer International Publishing AG; 2017. p. 1-31.

29. Davidson JRT, Stein DJ, Shalev AY, Yehuda R. Posttraumatic Stress Disorder: Acquisition, Recognition, Course, and Treatment. J Neuropsychiatry Clin Neurosci. 2004; 16(2):135-47.

30. Schlenger WE, Kulka RA, Fairbank JA, Hough RL, Jordan BK, Marmar CR, et al. The prevalence of posttraumatic stress disorder in the Vietnam generation: A multimethod, multisource assessment of psychiatric disorder. J Trauma Stress. 1992;5(3):333-63.

31. Feil $H$, Petti $M$, Park O. The Schneider index as modified by diseases of the circulation. Am Heart J. 1943;26(1):1-10.

32. Jain KK. Cerebral Air Embolism, Chapter 12. In: Jain KK, editor. Textbook of Hyperbaric Medicine. 6th ed. Cham, Switzerland: Springer International Publishing AG; 2017. p. 121-30.
33. James PB, Jain KK. Decompression Sickness, Chapter 11. In: Jain KK, editor. Textbook of Hyperbaric Medicine. 6th ed. Cham, Switzerland: Springer International Publishing AG; 2017. p. 101-20.

34. Gentry J, Rango J, Zhang J, Biedermann S. Latent presentation of decompres- sion sickness after altitude chamber training in an active duty flier. Aerosp Med Hum Perform. 2017;88(4):427-30.

35. Tawar A, Gokulakrishnan P. Decompression illness. J Mar Med Soc. 2019;21(2):112.

36. Smith TG, Chang RW, Robbins PA, Dorrington KL. Commercial air travel and in-flight pulmonary hypertension. Aviat Space Environ Med. 2013;84(1):65-7.

37. Schreijer A, Cannegieter S, Caramella M, Meijers $\mathrm{J}$, Krediet R, Simons R, et al. Fluid loss does not explain coagulation activation during air travel. Thromb Haemost. 2008; 99(06):1053-9.

38. Kam P, Power I. Special environments, Chapter 16. In: Kam P, Power I, editors. Principles of Physiology for the Anaesthetist. 2nd ed. Boca Raton, Florida: CRC Press; 2012. p. 429-435.

39. Street N. Book Review: Principles of Physiology for the Anaesthetist. Anaesth Intensive Care. 2008;36(3):466.

German Domínguez Vías. Doctor en Medicina por la Universidad de Cádiz.
Master Universitario en Avances en Seguridad de los Alimentos y Licenciado
en Biología por la Universidad de Jaén. Actualmente es profesor ayudante
doctor de la Facultad de Ciencias de la Salud de Ceuta de la Universidad de
Granada, donde imparte docencia asociada al departamento de fisiología
en el grado de enfermería, e implementa el Cine como recurso educativo
dentro del currículo. Su línea de investigación se centra en la neurodege-
neración y la regulación de la presión arterial.

Rev. Med. Cine. 2020; 16(4), 261-277 Ediciones Universidad de Salamanca / @@@@

J. Med. Mov., 2020; 16(4), 261-277

[ 277 ] 